DOI: 10.12731/2218-7405-2018-7-201-214

УДК 159. 9-057.87(045)

\title{
ПРОЕКТИРОВАНИЕ И РЕАЛИЗАЦИЯ ПРОГРАММЫ РАЗВИТИЯ ЛИЧНОСТНОЙ ГОТОВНОСТИ БУДУЩЕГО ПЕДАГОГА К ИННОВАЦИОННОЙ ДЕЯТЕЛЬНОСТИ В ПРОЦЕССЕ ИЗУЧЕНИЯ ПСИХОЛОГИЧЕСКИХ ДисцИПЛИН
}

\author{
Савинова Т.В., Кудашкина О.В., \\ Ерохина T.Г.
}

Цель. Статья посвящена развитию личностной готовности будущего педагога к инновационной деятельности. Данная проблема в настоящее время стала особо актуальной в связи с реформированием профессионального образования и его ориентированием на инновации.

Метод или методология проведения работы. Теоретический анализ литературы по проблеме исследования, проектирование программы развития личностной готовности будущего педагога к инновационной деятельности в процессе изучения психологических дисциплин.

Результаты. Разработанная в ходе исследования программа способствует развитию у будущих педагогов личностных качеств, необходимых для эффективной реализациии инновационной деятельности.

Область применения результатов. Результать исследования могут быть полезны преподавателям вузов и использоваться в процессе разработки и проведения психологических дисииплин; специалистами различных организащий для формирования кадровой политики и подбора персонала.

Ключевые слова: инновационная деятельность; личностная готовность; будущий педагог; психологические дисциплины; студент. 


\section{DESIGN AND IMPLEMENTATION OF THE PROGRAM OF DEVELOPMENT OF THE PERSONAL PREPAREDNESS FOR THE FUTURE TEACHER TO INNOVATIVE ACTIVITY IN THE PROCESS OF STUDYING PSYCHOLOGICAL DISCIPLINES}

\section{Savinova T.V., Kudashkina O.V., Erokhina T.G.}

Purpose. The article is devoted to the development of the personal readiness of the future teacher for innovative activities. This problem has now become particularly relevant in connection with the reform of vocational education and its orientation towards innovation.

Methodology. Theoretical analysis of literature on the problem of research, designing a program for developing the personal readiness of the future teacher for innovative activities in the process of studying psychological disciplines.

Results. The program developed during the research contributes to the development by the future teachers of innovative psychological and pedagogical technologies and the development of personal qualities necessary for the effective implementation of innovative activities.

Results implications. The program developed in the course of the research contributes to the development of the personal qualities necessary for effective implementation of innovative activity in future educators.

Keywords: innovation activity; personal readiness; the future teacher; psychological disciplines; student.

\section{Введение}

Проблема личностной готовности будущих педагогов к инновационной деятельности в последние годы стала особо актуальной в связи с реформированием профессионального образования и его ориентированием на инновации. Личностная готовность к инновационной деятельности является залогом успешной профессиональной деятельности и является результатом качественной специальной подготовки. 
Согласно Концепции долгосрочного развития Российской Федерации на период до 2020 года, утвержденной распоряжением Правительства Российской Федерации от 17 ноября 2008 г. № 1662-р, переход экономики государства на инновационный тип развития возможен только при условии формирования конкурентоспособной в глобальном масштабе национальной инновационной системы, ключевым фактором успешного функционирования которой является эффективная система воспроизводства конкурентоспособных на мировом уровне кадров научной и научно-образовательной сферы, привлечения и закрепления в науке талантливой молодежи, обеспечения повышения качества подготовки кадров высшей квалификации, в том числе в рамках научных и научнообразовательных структур высших учебных заведений [8].

Развитие личностной готовности студентов педагогического вуза к инновационной деятельности должно уже прочно войти в программу высшего профессионального образования и действовать в соответствии с современными требованиями общества и науки в частности.

\section{Обзор литературы}

Теоретический анализ отечественных и зарубежных источников свидетельствует о наличии устойчивого научного и практического интереса к изучению личностной готовности к инновационной деятельности. В настоящее время имеется ряд исследований, посвященных изучению инноваций (С.В. Романченко [10], С.Р. Яголковский [14], G. Mensch [15]), особенностей инновационной деятельности в образовании (Ю.В. Варданян [1], Н.В. Винокурова [2], Э.Ф. Зеер [6], Е.Т. Конюхова [6], О.И. Карпунина [7]), формированию готовности к инновационной профессиональной деятельности (В.И. Горовая [3], Н.Г. Пьянкова [3], Т.В. Савинова [12], Y.S.Tyunnikov [16]), внедрению инновационных педагогических технологий (И.Д. Дерновский [4], А.Н. Панфилова [9]). Однако анализ научных исследований и опыта педагогической деятельности позволяет констатировать, что возможности психологических дисциплин для развития личност- 
ной готовности студентов педагогического вуза еще недостаточно изучены, что повышает актуальность целенаправленного обращения к данному вопросу.

По мнению В.А. Сластенина, Л.С. Подымовой, инновационная направленность профессиональной деятельности педагогов в современных условиях развития общества и образования определяется рядом обстоятельств:

- социально-экономическими изменениями, которые способствуют возрастанию необходимости обновления всей системы образования, методов и приемов организации учебно-воспитательного процесса в образовательных учреждениях;

- постоянным изменением объема и состава учебных предметов, а также введением новых учебных дисциплин;

- изменением отношения педагогов к факту освоения и внедрения педагогических новшеств в собственную профессиональную деятельность;

- вхождением в рыночные отношения образовательных учреждений [13].

Личностная готовность к инновациям определяется положительным отношением к инновациям в собственной работе, готовностью их использовать, постоянным саморазвитием и стремлением создать качественно новый продукт или технологию [11].

Личностная готовность будущего педагога к инновационной деятельности представляет собой целостный психологический феномен, единство когнитивного (знание инноваций, способов их применения), аффективного (положительное отношение к инновациям) и деятельностного (владение инновационными педагогическими технологиями, креативность) компонентов.

Изучение психологических дисциплин позволяет будущим педагогам грамотно выстраивать образовательный маршрут с учетом всех особенностей личности. В рамках психологических дисциплин изучаются механизмы и закономерности процесса усвоения знаний, выявляются психологические особенности, оказывающие 
влияние на эффективность учебного процесса и развитие творческого мышления учащихся, а также изучаются проблемы взаимоотношений учащихся друг с другом и с педагогическим коллективом образовательной организации.

Вовлечение будущего педагога в инновационную деятельность в процессе изучения психологических дисциплин способствует повышению уровня профессиональной компетентности, активизирует его стремление к получению новых знаний, к самовыражению, самореализации при решении педагогических задач, к развитию творческого потенциала.

В.И. Загвязинский, Т.А. Строкова отмечают, что профессиональную деятельность учителя сложно назвать полноценной, если она строится только на принципах воспроизводства ранее усвоенных методов работы. Такая деятельность не эффективна в связи с тем, что в ней не используются существующие инновационные возможности, которые позволяют добиться более высоких результатов в образовании. Педагогический процесс, построенный с учетом современных образовательных потребностей и особенностей учеников, стимулирует интерес учащихся к учебным предметам, способствует повышению показателей успеваемости, развитию профессиональных компетенций педагога [5].

\section{Описание исследования}

Для определения личностной готовности будущих педагогов к инновационной деятельности в ходе исследования использовались следующие методики: тест «Диагностика инновационности субъекта» (М. Кёртон), тест «Диагностика личностной креативности» (Е.Е. Туник), методика «Шкала самооценки инновативных качеств личности» (Н.М. Лебедева, А.Н. Татарко).

По результатам проведенной диагностики можно сделать вывод о том, что преобладающая часть студентов характеризуется средним и низким уровнями инновационных характеристик: 42,3\% испытуемых являются слабовыраженными инноваторами, для 53,8\% студентов характерен средний уровень личностной креативности и 
инновативных качеств, а для 21,1\% испытуемых - низкий, что говорит о шаблонности мышления и отсутствии стремления к изучению и разработке инноваций.

С учетом полученных диагностических данных была разработана и реализована в рамках дисциплины «Психология» программа развития личностной готовности будущего педагога к инновационной деятельности. В исследовании приняли участи 52 студента 2 курса ФГБОУ ВО «Мордовский государственный педагогический институт им. М.Е. Евсевьева», направления подготовки 44.03.05 Педагогическое образование.

Основной целью программы являлось развитие личностной готовности будущих педагогов к инновационной деятельности.

Исходя из цели, были выделены следующие задачи программы:

- повышение профессиональной компетентности студентов по проблеме педагогических инноваций;

- выявление индивидуальных особенностей личностной готовности к инновационной деятельности;

- развитие таких компонентов личностной готовности к инновационной деятельности как: положительное отношение к инновациям, воображение, творческая направленность мышления.

Программа включала 4 раздела, соответствующие рабочей программе дисциплины «Психология»: общая психология, возрастная психология, социальная психология, педагогическая психология. В каждом разделе было представлено по 5 занятий, предусматривающих выполнение специальных заданий, направленных на развитие личностной готовности к инновационной деятельности. Общее количество занятий - 20. Продолжительность выполнения заданий: 30 минут. Форма работы варьировалась в зависимости от содержания занятия.

При организации занятий использовались такие технологии как: групповая дискуссия, мозговой штурм, «жужжащие» группы, решение педагогических проблемных ситуаций, метод анализа кейсов, игровое проектирование, метод «инцидента» и т. д. 
Исходя из сформулированного в ходе исследования определения личностной готовности будущего педагога к инновационной деятельности, в содержание программы включены задания, направленные на развитие ее когнитивного, аффективного и деятельностного компонентов. Приведем примеры некоторых заданий.

Раздел «Общая психология».

1. Тема «Воображение»: подготовка эссе на тему «Взаимосвязь инновационной деятельности и воображения».

2. Тема «Человек как субъект внутреннего мира»: анализ собственной готовности к инновационной деятельности; составление психолого-педагогических рекомендаций по развитию творческого потенциала личности.

3. Тема «Потребностно-мотивационная сфера личности»: групповая дискуссия: «Что может мотивировать педагога на создание инновационного проекта?».

4. Тема «Темперамент»: подготовка групповых проектов о типах темперамента и их предрасположенности к инновационной деятельности, анализ проектов с использованием технологии «жужжащие» группы.

5. Тема «Эмоции и чувства»: работа проблемных групп по темам: «Эмоциональная устойчивость как фактор развития личностной готовности к инновационной деятельности», «Способы эмоционального реагирования на инновации в образовательном учреждении».

Раздел «Возрастная психология».

1. Тема «Психология ребенка раннего возраста»: разработка авторской игры для развития одного из познавательных процессов ребенка раннего возраста.

2. Тема «Психология ребенка дошкольного возраста»: разработка инновационных проектов развивающих центров/детских садов и т. д. для детей дошкольного возраста.

3. Тема «Психология ребенка младшего школьного возраста»: разработка конспекта мероприятия для младших школьников, направленного на развитие творческого мышления учащихся. 
4. Тема «Психология подростков»: разработка и решение психологических кейсов на тему особенностей развития личностной сферы подростков.

5. Тема «Психология юности»: мозговой штурм: «Какие формы работы могут быть использованы для развития у юношей креативности и готовности к инновационной деятельности?».

Раздел «Социальная психология».

1. Тема «Психология общения»: групповая дискуссия: «Как уровень коммуникабельности может влиять на реализацию педагогом инновационной деятельности?»; модификация игр, направленных на развитие коммуникативных, интерактивных, перцептивных способностей.

2. Тема «Социальная психология групп»: определение условий и возможностей использования инновационных педагогических технологий при работе с малыми группами.

3. Тема «Проблемы личности в социальной психологии»: подбор методик и диагностика личностной готовности будущих педагогов к инновационной деятельности.

4. Тема «Социализация»: разработка кейсов по теме «Институты социализации, их инновационный потенциал».

5. Тема «Конфликты и стратегии их разрешения»: ролевая игра «Сглаживание конфликтов»; поиск эффективных способов разрешения конфликтов в образовательном процессе.

Раздел «Педагогическая психология».

1. Тема «Психологические основы педагогической деятельности»: построение маршрута саморазвития творческого потенциала учителя, разработка психолого-педагогических рекомендаций педагогам по развитию инновационного мышления.

2. Тема «Профессионально-педагогическое общение»: характеристика стилей профессионально-педагогического общения и определение их инновационной направленности.

3. Тема «Психология личности учителя»: составление характеристики учителя, нацеленного на инновационную деятельность; выявление причин, затрудняющих разработку и использование инновационных технологий. 
4. Тема «Проблемы профессионально-психологической компетенции и профессионально-личностного роста»: определение личностных характеристик педагога, способствующих эффективной реализации инновационной деятельности и способов их развития

5. Тема «Образование в современном мире»: составление психологического портрета инновационного учителя; подготовка списка литературы для педагогов по проблеме развития творческого потенциала и инновационности.

Таким образом, в процессе реализации данной программы будущие педагоги получают знания об инновациях и возможностях их реализации в образовательном процессе, знакомятся с современными инновационными технологиями, пробуют себя в роли настоящих проектировщиков и авторов инновационных проектов. В ходе заключительного занятия студенты получают памятки с психологопедагогическими рекомендациями для развития личностной готовности к инновационной деятельности.

Для определения эффективности программы был осуществлен сравнительный анализ данных испытуемых до и после ее реализации с использованием $\varphi^{*}$ критерия Фишера. Среди испытуемых снизилось количество слабовыраженных адапторов (1,943*), при этом увеличилось количество инноваторов $\left(2,014^{*}\right)$. Также увеличилось число студентов с высоким уровнем инновативных качеств личности $(1,882 *)$, в то время как количество испытуемых с низким уровнем значительно уменьшилось $(3,564 * *)$.

\section{Заключение}

В целом, разработанная в ходе исследования программа способствует развитию личностных качеств, необходимых для эффективной реализации инновационной деятельности. Результаты данного исследования могут быть полезны преподавателям вузов и использоваться в процессе разработки и проведения психологических дисциплин; специалистами различных организаций для формирования кадровой политики и подбора персонала. 
Информация о конфликте интересов. Авторы заявляют об отсутствии конфликта интересов.

Информация о спонсорстве. Исследование выполнено в рамках гранта на проведение научно-исследовательских работ по приоритетным направлениям научной деятельности вузов-партнеров по сетевому взаимодействию (Чувашский государственный педагогический университет имени И.Я. Яковлева и Мордовский государственный педагогический институт им. М.Е. Евсевьева) по теме «Развитие личностной готовности будущего педагога к инновационной деятельности в процессе изучения психологических дисциплин».

\section{Список литературы}

1. Варданян Ю.В. Инновационная деятельность научно-образовательного комплекса: истоки, опыт и перспективы развития // Гуманитарные науки и образование. 2012. № 2(10). С. 35-41.

2. Винокурова Н.В. О возможностях инновационного развития педагогических вузов // Гуманитарные науки и образование. № 2(6). 2011. С. 14-17.

3. Горовая В.И., Пьянкова Н.Г. О подготовке студентов к инновационной профессиональной деятельности // Вестник Костромского государственного университета им. Н.А. Некрасова. 2008. № 2. С. 51-57.

4. Дерновский И.Д. Инновационные педагогические технологии. Киев: Академвидав, 2004. 352 с.

5. Загвязинский В.И., Строкова Т.А. Педагогическая инноватика: проблемы стратегии и тактики. Тюмень: ТГУ, 2011. 176 с.

6. Зеер Э.Ф., Конюхова Е.Т. Психологические факторы влияния установки педагогов на инновационную деятельность // Образование и наука. 2010. № 4. С. 41-50.

7. Карпунина О.И. Факультет психологии и дефектологии: инновации и перспективы развития // Гуманитарные науки и образование. 2012. №2(10). C. 28-31.

8. Концепция федеральной целевой программы «Научные и научнопедагогические кадры инновационной России» на 2014-2020 годы. 
URL: http://www.rg.ru/pril/ 81/02/04/760_koncepciia.pdf/ (дата обращения: 20.06.2018).

9. Панфилова А.Н. Инновационные педагогические технологии. М.: Академия, 2012. 191 с.

10. Романченко С. В. Новшества, нововведении, инновации: определения и сущность // Молодой ученый. 2012. № 4. С. 166-168.

11. Савинова Т.В., Ерохина Т.Г. Исследование личностной готовности будущих педагогов к инновационной деятельности как компонента профессиональной стратегии // Проблемы современного педагогического образования. Ялта: РИО ГПА. 2017. Вып. 57. Ч. 13. C. $183-189$.

12. Савинова Т.В., Пильщикова Г.В. Тренинг как технология развития инновационного мышления студентов // Гуманитарные науки и образование. 2015. № 4(24). С. 87-90.

13. Сластенин В.А., Подымова Л.С. Педагогика: инновационная деятельность. М.: Магистр, 1997. 224 с.

14. Яголковский С. Р. Психология инноваций: подходы, модели, процессы. М.: ГСПИ, 2010. 263 с.

15. Mensch G. Theory of Innovation. Berlin: International Institute of Management, 1983. $184 \mathrm{p}$.

16. Tyunnikov Y.S. Integral assessment of future teachers' professional preparation for innovative activity // European journal of contemporary education. No 3. 2013, pp. 183-200.

\section{References}

1. Vardanyan Yu.V. Innovative activity of the scientific and educational complex: sources, experience and development prospects. Gumanitarnye nauki i obrazovanie [The Humanities and Education]. 2012. No 2(10), pp. 35-41.

2. Vinokurova N.V. On the possibilities of innovative development of pedagogical universities. Gumanitarnye nauki i obrazovanie [The Humanities and Education]. 2011. No 2 (6), pp. 14-17.

3. Gorovaya V.I., Pyankova N.G. On the preparation of students for innovative professional activity. Vestnik Kostromskogo gosudarstvennogo 
universiteta im. N.A. Nekrasova [Bulletin of Kostroma State University N.A. Nekrasov]. 2008. No 2, pp. 51-57.

4. Dernovsky I.D. Innovatsionnye pedagogicheskie tekhnologii [Innovative pedagogical technologies]. Kiev: Akademvidav, 2004. 352 p.

5. Zagvyazinsky V.I., Strokova. T.A. Pedagogicheskaya innovatika: problemy strategii i taktiki [Pedagogical Innovation: Problems of Strategy and Tactics]. Tyumen: TGU, 2011. 176 p.

6. Zeer E.F., Konyukhova E.T. Psychological factors of the influence of the installation of teachers on innovation activity. Obrazovanie i nauka [Education and Science]. 2010. No 4, pp. 41-50.

7. Karpunina O.I. Faculty of Psychology and Defectology: Innovations and Development Prospects. Gumanitarnye nauki i obrazovanie [The Humanities and Education]. 2012. No 2(10), pp. 28-31.

8. Kontseptsiya federal'noy tselevoy programmy «Nauchnye i nauchno-pedagogicheskie kadry innovatsionnoy Rossii» na 2014-2020 gody [The concept of the federal target program «Scientific and scientific-pedagogical staff of innovative Russia» for 2014-2020]. http://www.rg.ru/ pril/ 81/02/04/760_koncepciia.pdf/ (accessed June 20, 2018).

9. Panfilova A.N. Innovatsionnye pedagogicheskie tekhnologii [Innovative pedagogical technologies]. M.: Academy, 2012. 191 p.

10. Romanchenko S.V. Innovation, innovations, innovations: definitions and essence. Molodoy uchenyy [Young Scientist]. 2012. No 4, pp. 166168.

11. Savinova T.V., Erokhina T.G. Research of personal readiness of future teachers for innovative activity as a component of professional strategy. Problemy sovremennogo pedagogicheskogo obrazovaniya [Problems of Modern Pedagogical Education]. Yalta: RIO GPA. 2017. No 57(13), pp. 183-189.

12. Savinova T.V., Pil'shchikova G.V. Training as a technology for the development of innovative thinking of students. Gumanitarnye nauki i obrazovanie [The Humanities and Education]. 2015. No 4(24), pp. 87-90.

13. Slastenin V.A., Podymova L.S. Pedagogika: innovatsionnaya deyatel'nost' [Pedagogy: innovation activity]. M.: Master, 1997. 224 p. 
14. Yagolkovsky S.R. Psikhologiya innovatsiy: podkhody, modeli, protsessy [Psychology of Innovation: Approaches, Models, Processes]. M.: GSPI, 2010. $263 \mathrm{p}$.

15. Mensch G. Theory of Innovation. Berlin: International Institute of Management, 1983. $184 \mathrm{p}$.

16. Tyunnikov Y.S. Integral assessment of future teachers' professional preparation for innovative activity. European journal of contemporary education. No 3. 2013, pp. 183-200.

\section{ДАННЫЕ ОБ АВТОРАХ}

Савинова Татьяна Викторовна, доцент, кандидат психологических наук, доцент

Федеральное государственное бюджетное образовательное учреждение выстего образования «Мордовский государственный педагогический институт им. М.Е. Евсевьева»

ул. Студенческая, 11 «А», г. Саранск, 430007, Российская Федерачия

stanya2610@yandex.ru

Кудашкина Ольга Васильевна, доцент, кандидат психологических наук Федеральное государственное бюджетное образовательное учреждение выстего образования «Мордовский государственный педагогический институт им. М.Е. Евсевьева»

ул. Студенческая, 11 «А», г. Саранск, 430007, Российская Федерачия

kudashkinao@yandex.ru

\section{Ерохина Татьяна Геннадьевна, магистрант}

Федеральное государственное бюджетное образовательное учрежжение выстего образования «Мордовский государственный педагогический институт им. М.Е. Евсевьева» ул. Студенческая, 11 «А», г. Саранск, 430007, Российская Федерачия erohina.tatyana1994@yandex.ru 


\section{DATA ABOUT THE AUTHORS}

Savinova Tatyana Viktorovna, Associate Professor, Candidate of Psychological Sciences, Associate Professor

Mordovian State Pedagogical Institute named after M.E. Evseviev 11A, Studencheskaya Str., Saransk, 430007, Russian Federation stanya2610@yandex.ru

ORCID: 0000-0003-1578-3274

Kudashkin Olga Vasilyevna, Associate Professor, Candidate of Psychological Sciences

Mordovian State Pedagogical Institute named after M.E. Evseviev 11A, Studencheskaya Str., Saransk, 430007, Russian Federation kudashkinao@yandex.ru

ORCID: 0000-0001-6792-6068

Erokhina Tatyana Gennadievna, Graduate Student

Mordovian State Pedagogical Institute named after M.E. Evseviev 11A, Studencheskaya Str., Saransk, 430007, Russian Federation erohina.tatyana1994@yandex.ru 